\title{
Development of a solar concentrator with tracking system
}

\author{
Flávia V. Barbosa ${ }^{1}$, João L. Afonso ${ }^{2}$, Filipe B. Rodrigues $^{2}$, and José C. F. Teixeira ${ }^{1}$ \\ ${ }^{1}$ Department of Mechanical Engineering, School of Engineering, University of Minho, \\ Guimarães, 4800-058, Portugal \\ ${ }^{2}$ Department of Industrial Electronics, School of Engineering, University of Minho, \\ Guimarães, 4800-058, Portugal \\ Correspondence to: Flávia V. Barbosa (flavia.barbosa.ep@gmail.com)
}

Received: 3 June 2016 - Revised: 7 October 2016 - Accepted: 16 October 2016 - Published: 17 November 2016

\begin{abstract}
Solar Energy has been, since the beginning of human civilization, a source of energy that raised considerable interest, and the technology used for their exploitation has developed constantly. Due to the energetic problems which society has been facing, the development of technologies to increase the efficiency of solar systems is of paramount importance. The solar concentration is a technology that has been used for many years by the scientist, because this system enables the concentration of solar energy in a focus, which allows a significant increase in energy intensity. The receiver, placed at the focus of the concentrator, can use the stored energy to produce electrical energy through Stirling engine, for example, or to produce thermal energy by heating a fluid that can be used in a thermal cycle. The efficiency of solar concentrators can be improved with the addition of a dual axis solar tracker system which allows a significant increase in the amount of stored energy. In response to the aforementioned, this paper presents the design and construction of a solar dish concentrator with tracking system at low cost, the optical and thermal modelling of this system and a performance analysis through experimental tests. The experimental validation allows to conclude that the application of a tracking system to the concentrator is very important since a minimum delay of the solar radiation leads to important losses of system efficiency. On the other hand, it is found that the external factors can affect the final results which include the optical and geometrical properties of the collector, the absorptivity and the position of the receiver as well as the weather conditions (essentially the wind speed and clouds). Thus, the paper aims to present the benefits of this technology in a world whose the consumption of energy by fossil fuels is a real problem that society needs to face.
\end{abstract}

\section{Introduction}

During the last decades the huge development of the society led to an increase in energy consumption. For many years oil, coal and natural gas provided the backbone of the energy resources. The intense release of pollutant gases by these resources, including $\mathrm{CO}_{2}$, contributed, on one hand, to the increase of the greenhouse effect, raising the melting of the polar ice caps, and on the other hand to the deterioration of the air properties, producing, in extreme cases and with other harmful gases, like $\mathrm{NO}_{x}$, the smog (Allaby, 2003). These effects, along with the volatility of the oil price, alarmed the developed countries in the search for "clean" energetic solu- tions and led to an intense research to find sustainable renewable alternatives. Among the various forms of energy (solar, biomass, geothermal, wave and tidal, wind and water), the solar energy is certainly the most important source of energy, because all the others depend on it. The sun continuously emits energy at a temperature of about $5800 \mathrm{~K}$, being called solar radiation (Nogueira, 2010). Solar radiation can be used through solar photovoltaic and solar thermal systems. Solar photovoltaic systems directly generate electricity through photovoltaic cells, while solar thermal systems need to heat a fluid to produce thermal energy, which can be used as a heat source or in a thermal cycle, but also to produce electricity by a Stirling engine (Fernandes et al., 2009; Kalogirou, 2014). 
Through the concentration of solar beams, it is possible to increase the energy density (Kalogirou, 2014) and, in turn, the heat source temperature. Since this is a technology that can be exploited for thermal and electrical conversion and that uses a completely clean and inexhaustible source of energy, it is undoubtedly a solution which can contribute to minimize the consumption of fossil fuels.

Several technologies of Concentrating Solar Power (CSP) are implemented at industrial level. The great advantage of these technologies is the combined production of heat and power (CHP) to fulfil energy demands while providing various environmental, functional and economic benefits (Ferreira et al., 2016). Four CSP technologies are available for such purpose. Solar power towers, used to produce electrical energy, present potential advantages over others CSP technologies in terms of efficiency, heat storage, performance, capacity factors and costs. Fresnel linear reflectors and parabolic through types are applied in steam supply applications for industrial processes (Fernandes et al., 2009; Simbolotti, 2013). Parabolic through solar collectors are widely implemented across the world by industry, mostly in space heating and cooling, water desalination, food processing and fish, metal industry and products, pharmaceutical processing and dairy products (Kurup and Turchi, 2015). Despite of their high efficiency (up to $30 \%$ ), solar dishes have not yet been implemented on large commercial scale. However, they have been applied for electricity generation through Stirling engines or micro-turbines (Simbolotti, 2015). Although this technology is not widely applied at industrial level, it is important to note that the use of solar dish concentrators are a promising solution for residential applications mainly because of their high net efficiency, favourable ratio of thermal to electrical power, similar to a typical heat-to-electricity demand ratio of a domestic load, and low noise and emissions (Ferreira et al., 2015).

The demand for economically viable solutions in the development branch of solar dish concentrators has been increasing. Ripasso Company developed a new hybrid Stirling which allows a solar-to-grid electricity conversion of approximately $32 \%$, a fuel conversion ratio of $35 \%$ and without water needed for electricity production (Ripasso, 2016). Solartron Company developed a dual axis hybrid solar dish concentrator that provides $45 \mathrm{~kW}$ of thermal energy through a direct heat and free piston Stirling engine, with thermal fluid heating (i.e. in solar power plants that utilize high temperature heat such as ORC - Organic Rankine Cycle). Its main applicability is water desalination, Solar Enhanced Oil Recovery, water heating and the electricity production (Solartron, 2010).

To raise the performance of solar concentrators and make viable their implementation, it is necessary to couple a tracking system. Solar trackers position the system in order to maximize the energy capture. There are different types of solar trackers that can be organized in one or two axis motion (Mousazadeh et al., 2009). Depending on the solar concen- trator type, one or another system will be favoured. However, there is no doubt that the two axis system is the most efficient, since it follows the sun as its azimuthal movement and altitude, but its complexity increases its cost (Kalogirou, 2014). Two axis tracking system is widely implemented in solar thermal tower power plant and solar dish systems, since these technologies require the concentration of solar rays in a focus. To ensure the maximum performance of the system it is extremely important to ensure a correct sun tracking with minimal errors. For that purpose it is crucial to implement a good control system, which involves the application of a controller, sensors and motors, preferably at low cost.

In Portugal, the investment in solar trackers for photovoltaic panels has increased exponentially in the last decade, despite of the performance of photovoltaic modules, with the largest market share, to be approximately $15 \%$ (Fraunhofer ISE, 2015). Unfortunately, at a national level, the application of solar concentrators with tracking system for thermal application has not yet developed. This aspect has often been neglected in Portugal, since it does not exist any solar thermal plant or solar dish concentrators all over the country (CSP World, 2015). Since Portugal is one of the European countries with higher levels of irradiation $\left(1300-1800 \mathrm{kWh} \mathrm{m}^{-2}\right.$ ) (SolarGis, 2010) the question that arises is: "why the solar concentrator system are not used?", since they have a much higher energy use compared to photovoltaic systems.

Taking into consideration the solar potential of Portugal and the high efficiency of solar dishes, this work pretends to demonstrate the added-value of the application of this CSP technology. The development of a solar dish concentrator with a low cost tracking system allows to increase its application and disseminate the system into a wider market. It is hoped that this work will enhance the awareness of the private and industrial users to the technology and help to disseminate it.

\section{Solar concentrator}

\subsection{Solar dish collector}

The solar dish collector, as shown in Fig. 1, is a focus collector with dual axis solar tracker, allowing solar radiation to focus on the receiver located at the dish's focal point. In order to collect maximum radiation and convert into heat, the parabolic structure completes the entire tracking of the sun's path, optimizing the energy harvesting for thermal applications. The receiver absorbs the solar energy and converts it into thermal energy through a working fluid. This thermal energy is then converted into electricity by the use of a Stirling engine or through an OCR plant. This component must be designed to ensure the maximum absorption of solar radiation and the minimum heat losses to the environment, and its structure varies according to the working fluid and depends on the system application. This technology can yield temperatures above $1500^{\circ} \mathrm{C}$ (Stine and Geyer, 2001). 


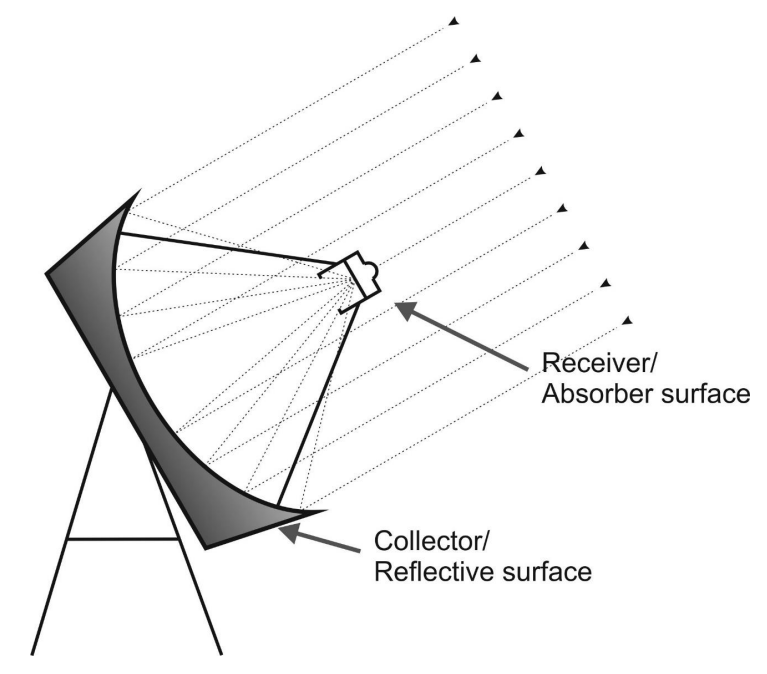

Figure 1. Solar dish collector representation.

Solar dish concentrators are used to achieve high temperatures and this concentration of solar radiation is accomplished by reflecting or refracting the incident flux on the aperture area (reflective surface) onto a smaller absorber area (receiver). To ensure maximum system efficiency, the understanding of all phenomena involved in this process is crucial. To understand the solar radiation conversion process through the collector and the thermal performance of the receiver, all the essential physical principles are discussed in this paper.

\subsection{Optical modelling}

Some optical parameters related to the collector need to be considered during the study of the solar dish collector.

\subsubsection{Concentration ratio}

The term concentration ratio is used to describe the amount of solar radiation concentrated by a particular concentrator. Two different definitions of concentration ratio are often used, briefly defined as follows (Rabl, 1976):

- Optical concentration ratio $\left(\mathrm{CR}_{\mathrm{o}}\right)$ : relation between the incident beam radiation on the reflective surface area $\left(I_{\text {sur }}\right)$ and the radiation that reaches the receiver $\left(I_{\text {rec }}\right)$, Eq. (1):

$$
\mathrm{CR}_{\mathrm{o}}=\frac{I_{\mathrm{rec}}}{I_{\mathrm{sur}}}
$$

- Geometric concentration ratio $(\mathrm{CR})$ : relation between the capture area of the collector $(A)$ and the receiver area $\left(A_{\text {rec }}\right)$, Eq. (2):

$$
\mathrm{CR}=\frac{A}{A_{\text {rec }}} \text {. }
$$

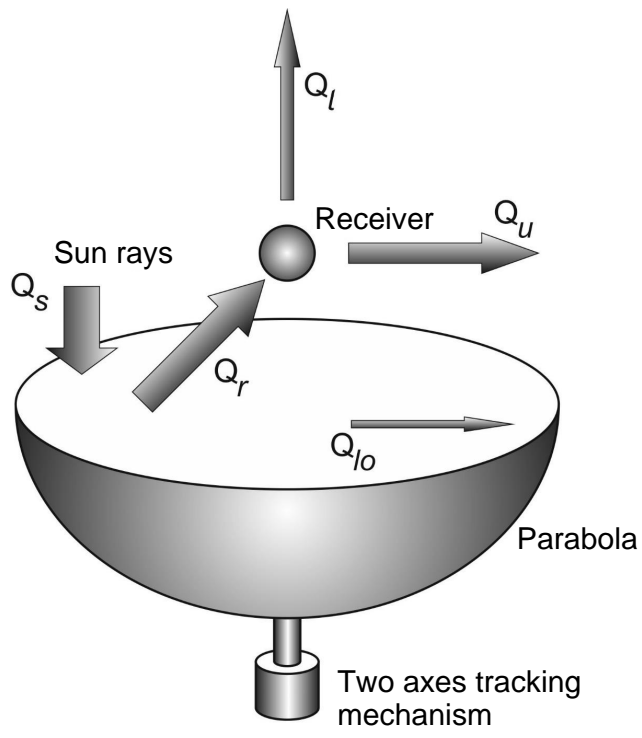

Figure 2. Energy balance of the solar dish concentrator (adapted from Thakkar, 2015).

Since the thermal losses are an important factor in the design of solar concentrators, the term of concentration ratio used along this work will be the geometric concentration ratio, $\mathrm{CR}$

\subsubsection{Optical efficiency $\left(\eta_{0}\right)$}

This parameter defines the performance of the collector through the quantification of the radiation captured by the reflective surface and the radiation that is reflected onto the receiver (Thakkar, 2015). For that, several parameters need to be considered, as defined in Eq. (3):

$\eta_{\mathrm{o}}=\rho_{\mathrm{s} \_\mathrm{m}} \cdot \tau_{\mathrm{g}} \cdot \alpha_{\mathrm{r}} \cdot S$

where $\rho_{\mathrm{S}_{-} \mathrm{m}}$ is the collector specular reflectance, $\tau_{\mathrm{g}}$ is the transmittance of glass envelope covering the receiver (if present), $S$ is the receiver shading factor (fraction of collector aperture not shielded by the receiver), and $\alpha_{\mathrm{r}}$ is the absorptivity of the receiver (Mohamed et al., 2012).

\subsection{Thermal modelling}

The solar radiation incident on the collector is reflected into a single point on the receiver. Because the reflecting surface is not perfect, part of the radiation will be dissipated and the fraction absorbed by the receiver is known as optical heat. Due essentially to the heat losses by radiation and convection, part of the incident energy on the receiver will be lost to the surroundings. The energy balance of the system is illustrated by Fig. 2 . 


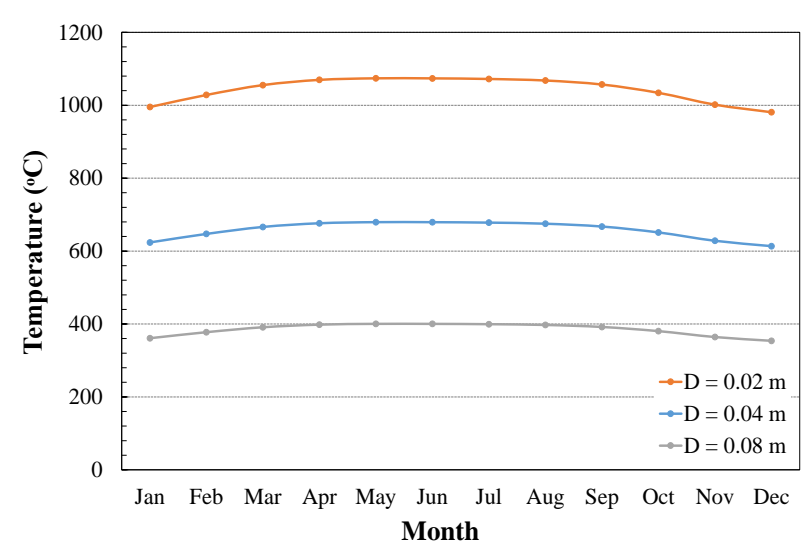

Figure 3. Maximum theoretical temperature reached by the receiver as a function of its absorber diameter.

\subsubsection{Useful heat}

Under steady state conditions, the useful heat $\left(Q_{\mathrm{u}}\right)$ delivered by a solar collector system is equal to the energy absorbed by the heat transfer fluid, which is determined by the radiant solar energy falling on the receiver (optical heat, $Q_{\mathrm{r}}$ ) minus the direct or indirect heat losses from the receiver to the surroundings $\left(Q_{1}\right)$, as presented in Eq. (4) (Thakkar, 2015):

$Q_{\mathrm{u}}=Q_{\mathrm{r}}-Q_{1}$.

The optical energy absorbed by the receiver is obtained by Eq. (5) (Thakkar, 2015):

$Q_{\mathrm{r}}=A_{\mathrm{ac}} \cdot \eta_{\mathrm{o}} \cdot I_{\mathrm{b}}$,

where $A_{\mathrm{ac}}$ is the dish collector aperture area, $\eta_{\mathrm{o}}$ the collector's optical efficiency and $I_{\mathrm{b}}$ the direct normal insolation per unit of collector area; furthermore the heat losses from the receiver to the surroundings $\left(Q_{1}\right)$ result of three heat transfer processes, conduction, convection and radiation, given by Eq. (6) (Gorjan et al., 2013).

$Q_{1}=Q_{\text {conduction }}+Q_{\text {convection }}+Q_{\text {radiation }}$.

\subsubsection{Heat losses}

Due to the concentration of solar rays in a small area, the receiver, the absorber area of this component can reach extremely high temperatures. To know the maximum theoretical temperature that the receiver can reach and in which proportion the diameter of the absorber area influences this temperature, a study was developed and presented in Fig. 3, in which three dimension were considered: the theoretical dimension of the receiver $(0.02 \mathrm{~m})$, the practical value adopted $(0.04 \mathrm{~m})$ and twice the practical value $(0.08 \mathrm{~m})$. These results are obtained through the application of the collector's dimensions used for the practical experiments and Eq. (7) (Steinfeld and Schubnell, 1993). From this analysis it is possible to

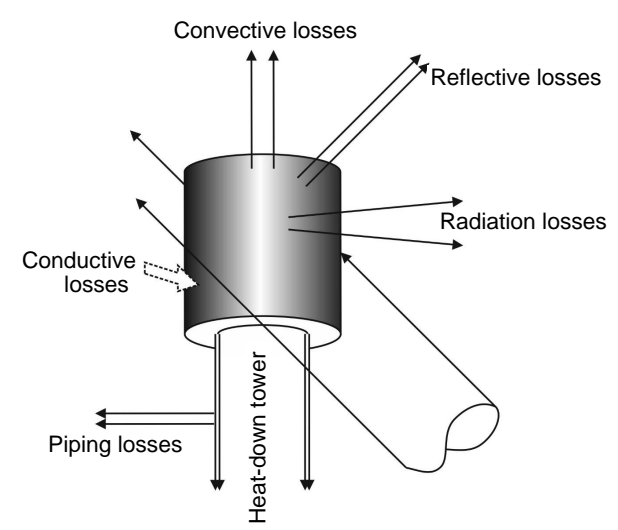

Figure 4. Receiver energy balance (adapted from Gorjan et al., 2013).

conclude that, as expected, an increase of the receiver's dimensions in relation to the ideal size (CR decreases with the increasing of the receiver diameter, since the collector diameter is constant) leads to a lower concentration of temperatures, i.e. a higher dissipation of heat concentration through the material.

$T_{\mathrm{rec}}=\left(\frac{\mathrm{CR} \cdot Q_{\mathrm{r}}}{\varepsilon \cdot \sigma}\right)^{1 / 4}$

where CR is the geometric concentration ratio, $Q_{\mathrm{r}}$ the optical energy absorbed by the receiver, $\varepsilon$ the emittance of the absorber surface and $\sigma$ the Stefan-Boltzmann constant $\left(5.670367 \times 10^{-8} \mathrm{~W} \mathrm{~m}^{-2} \mathrm{~K}^{-4}\right)$.

Because of its temperature, the receiver is the component responsible for the largest heat losses to the environment. There are many types of heat losses by the receiver presented in the energy balance illustrated in Fig. 4, which necessarily have to be minimized to ensure a high performance of the system (Thakkar, 2015). The main processes that affect the receiver's thermal losses are conduction, convection and radiation. However, since convection and radiation losses are much higher than conduction losses this last process was not considered in this study.

\section{Convective heat losses}

The convection losses can be obtained by Eq. (8) (Gorjan et al., 2013), in which $h_{\mathrm{cv}}$ is the convective heat transfer coefficient between the receiver and the environment, Eq. (9) (Cengel, 2015):

$Q_{\mathrm{cv}}=h_{\mathrm{cv}} \cdot A_{\mathrm{rec}} \cdot\left(T_{\mathrm{rec}}-T_{\mathrm{amb}}\right)$,

$h_{\mathrm{cv}}=\frac{N u_{\mathrm{D}} \cdot k_{\mathrm{ar}}}{D}$,

where $N U_{\mathrm{D}}$ is the Nusselt number, $k_{\mathrm{ar}}$ is the thermal conductivity of the air and $D$ the diameter of the absorber surface.

Two regimes of convection can be considered, forced and natural. For natural convection (when air is stagnant), the 


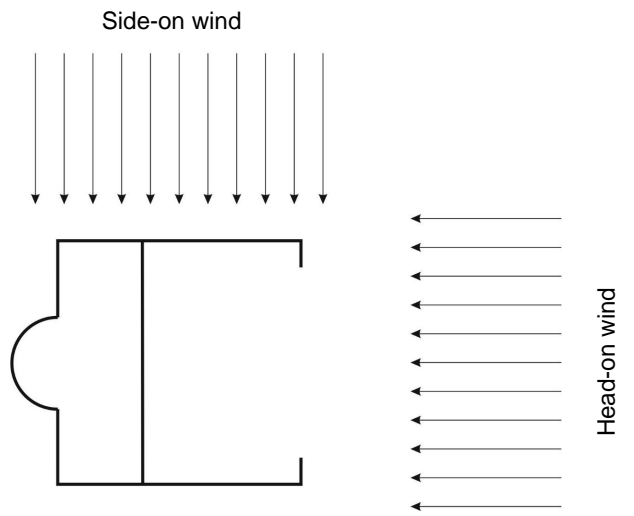

Figure 5. Effect of forced convection losses on receiver (adapted from Robbert, 1993).

heat transfer coefficient, $h_{\mathrm{cv} \text {, nat }}$, can be calculated by a correlation defined by Eq. (10) for laminar flow $\left(10^{4}<\operatorname{Gr} P r<\right.$ $\left.10^{9}\right)$ and Eq. (11) for turbulent flow $\left(\operatorname{Gr} \operatorname{Pr}>10^{9}\right)$, where $G r$ and $P r$ are respectively the Grashof and Prandtl numbers (Holman, 1976):

$h_{\mathrm{cv}, \text { nat }}=1.42 \cdot\left(\frac{\Delta T}{L}\right)^{1 / 4}$,

$h_{\mathrm{cv}, \text { nat }}=0.95 \cdot(\Delta T)^{1 / 3}$,

where $\Delta T$ is the temperature difference between the wall and the air $\left({ }^{\circ} \mathrm{C}\right)$ and $L$ the vertical dimension $(\mathrm{m})$.

Heat losses by forced convection occur due to the wind flux around the receiver. The wind flow has two direction, side-on wind and head-on wind, as it can be seen in Fig. 5.

To calculate the heat losses by convection due to side-on wind, the bottom side of the receiver has been assumed as a flat plate which is exposed to the parallel flow. The value of average Nusselt number for laminar flow $\left(\operatorname{Re}<5 \times 10^{5}\right)$ on a flat plate is equal to Eq. (12), and that for turbulent flow $\left(5 \times 10^{5}<R e<10^{7}\right)$ is calculated by Eq. (13) (Gorjan et al., 2013).

$N u_{\mathrm{D}}=0.0664 \cdot \operatorname{Re}_{\mathrm{D}}^{0.5} \cdot \operatorname{Pr}^{1 / 3}$

$N u_{\mathrm{D}}=0.037 \cdot R e_{\mathrm{D}}^{0.8} \cdot \operatorname{Pr}^{1 / 3}$

In the case of head-on flow, Hess (1973) proposed the Eq. (14) which is function of the Peclet number $(\mathrm{Pe})$. In this equation, it is assumed that the fluid flow is laminar and irrotational and the fluid is incompressible and inviscid.

$N u_{\mathrm{D}}=1.2 \cdot P e_{\mathrm{D}}^{0.5}$

\section{Radiation heat losses}

These losses are related to the fourth of the temperature power of the receiver surface, Eq. (15). However, they can be minimized by increasing the receiver absorptivity and by

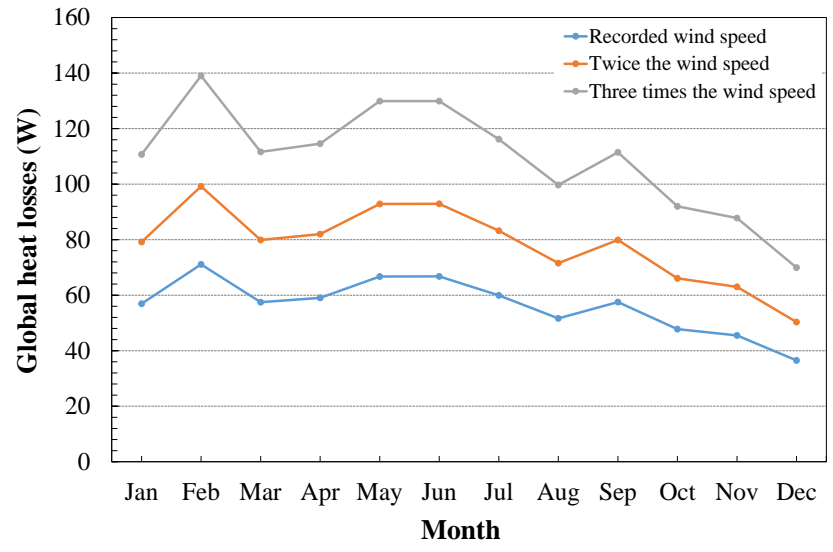

Figure 6. Theoretical analysis of the influence of the wind speed in the system heat losses.

minimizing the absorber area. To determine the heat losses by radiation, it is first necessary to calculate the radiation coefficient, $h_{\mathrm{r}}$, through Duffie equation given by Eq. (16), where $\varepsilon$ is the emittance of the absorber surface, $\sigma$ is the Stefan-Bolzmann constant and $T_{\mathrm{amb}}$ is the ambient temperature (Duffie and Beckman, 1991).

$Q_{\text {radiation }}=h_{\mathrm{r}} \cdot A_{\text {rec }} \cdot\left(T_{\text {rec }}-T_{\mathrm{amb}}\right)$

$h_{\mathrm{r}}=4 \cdot \sigma \cdot \varepsilon \cdot T_{\mathrm{amb}}^{3}$

As it is known, the wind speed influences the heat losses by convection, since the higher the wind speed, the higher the convection coefficient. To analyse the influence of this parameter in the global heat losses, a parametric study was performed (Fig. 6), in which the average wind speed recorded in Braga (city located in northern Portugal) in each month of 2015 was considered, velocities two and three times higher were also considered. The results obtained prove that the increase of the wind speed greatly influences the heat losses. For the case of twice the wind speed, the heat losses increases in average about 20 and $50 \mathrm{~W}$ when the speed is tripled.

\section{.3 Thermal efficiency}

The thermal efficiency in solar dish concentrators can be defined in two different ways (Gorjan et al., 2013):

- Thermal collector efficiency: ratio between the useful energy delivered to the fluid and the total energy captured by the reflective surface, as expressed by Eq. (17).

$$
\eta_{\text {concentrator }}=\frac{Q_{\mathrm{u}}}{A_{\mathrm{ac}} \cdot I_{\mathrm{b}}}
$$

- Thermal receiver efficiency: ratio between the useful energy delivered from the receiver to the fluid and the energy falling on the receiver, Eq. (18).

$$
\eta_{\text {receiver }}=\frac{Q_{\mathrm{u}}}{A_{\mathrm{ac}} \cdot I_{\mathrm{b}} \cdot \eta_{\mathrm{o}}}
$$




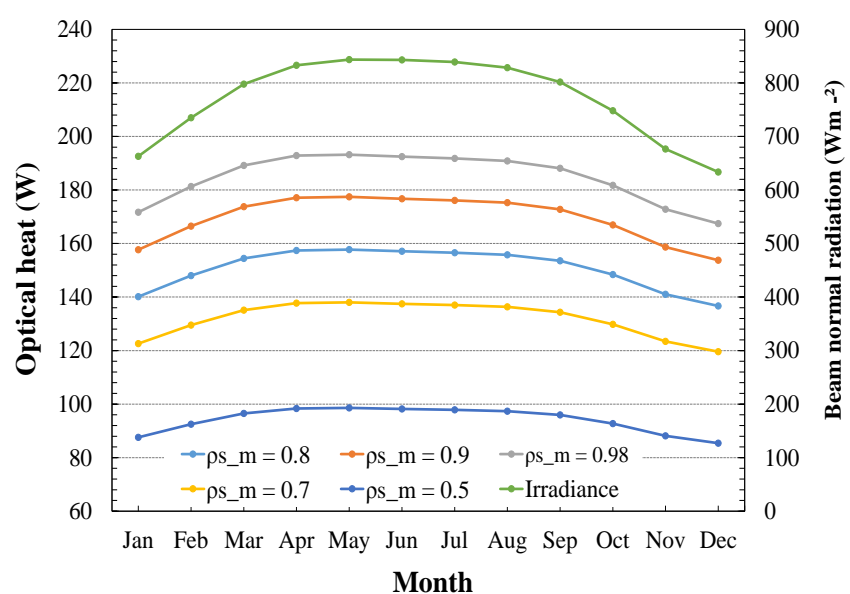

Figure 7. Optical heat variation as a function of the collector reflectivity.

\section{Solar concentrator components}

\subsection{Collector}

The concentrator prototype is a small diameter parabola with an offset structure to minimize the efficiency losses due to the shadowing effect. As presented in Eq. (5) the optical energy of the solar concentrator is given as a function of the collector's reflectivity. To analyse into which extent this parameter affects the concentrator optical heat, a theoretical analysis was developed considering five reflectivity values $(0.5,0.7$, 0.8, 0.9 and 0.98). Through the results presented in Fig. 7, it is observed that the optical energy decrease approximately $10 \%$ per decrease of 0.1 of the reflectivity value, compared to the best scenario $\left(\rho_{\mathrm{s} \_\mathrm{m}}=0.98\right)$, which can lead to a loss of optical heat of $50 \%$ for a reflectivity value of 0.5 .

Due to the paramount importance of this parameter in the system performance, an experimental study will be presented below, in which two reflective surfaces were considered. One was covered with aluminium foil $\left(\rho_{\mathrm{s} \_\mathrm{m}}=0.8\right)$, and another was coated with galvanized silver $\left(\rho_{\mathrm{s}_{-} \mathrm{m}}=0.96\right)$.

\subsection{Receiver}

The type of solar receiver usually used in solar concentrators is of cavity type. However, in this project, a new receiver type, which allows the absorption of solar radiation through a surface composed by a high heat conductive material, was designed and constructed (Fig. 8). This surface transfers the heat absorbed to a working fluid (water) through a finned surface. To minimize losses to the outside, the metallic receiver is insulated with rock wool, because of its low thermal conductivity.

In solar receivers, losses by convection have a considerable importance, but particularlly in this type since the absorber area, which consists of a copper cylinder, is in direct contact with the environment. So any change in the environ-

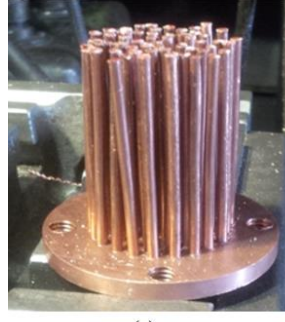

(a)

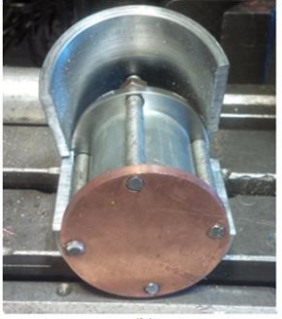

(b)

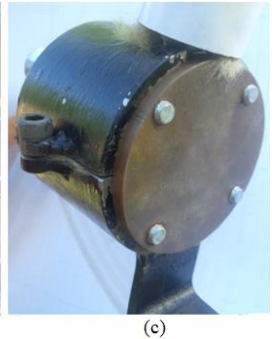

(c)
Figure 8. Solar receiver: (a) cooper fins, (b) internal structure, (c) external insulation.

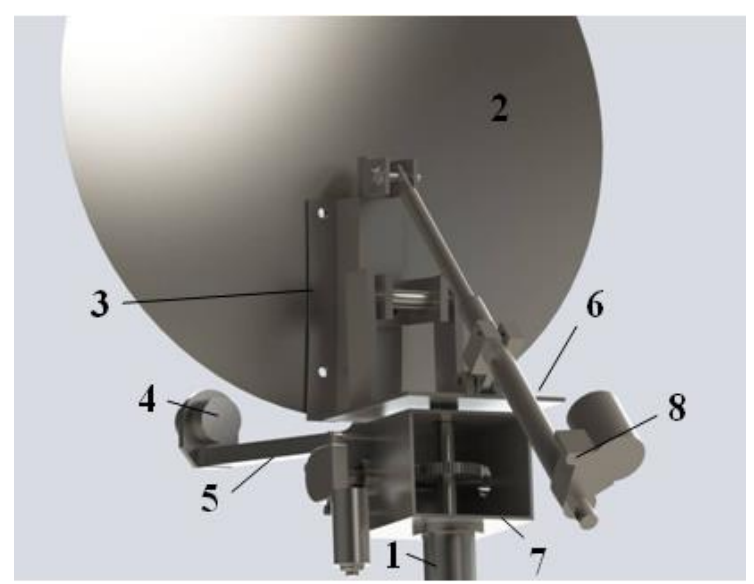

Figure 9. Solar tracker structure.

ment will have important repercussions on the heat absorbed by the receiver. If the wind speed increases or if a cloud interfers with the solar radiation, the useful heat will be reduced, as well as the system performance.

\subsection{Solar tracker structure}

For the design of the solar tracker structure two forces need to be considered: the system weight and the aerodynamic force. The total mass supported by the mast, Fig. 9 (1), is obtained by adding the mass of the dish (2), the support dish (3), the receiver (4), the receiver support (5), the base support (6), the linear actuator (7) and the reduction gear (8). Thus the total mass of the system is $30.5 \mathrm{~kg}$ so the system weight is $301 \mathrm{~N}$. Regarding the aerodynamic force, this is less predictable as it acts on the dish in different directions. However, the critical situation is when the wind flows perpendicularly to the collector when it is positioned vertically. To calculate this force, Eq. (19) was applied, considering the air density $(\rho)$ of $1.2 \mathrm{~kg} \mathrm{~m}^{-3}$, an air speed $(v)$ of $100 \mathrm{kmh}^{-1}$, an aerodynamic coefficient of parabolic dish $\left(C_{\mathrm{D}}\right)$ of about 0.95 and its area (A) as $0.342 \mathrm{~m}^{2}$.

$F_{\text {ae }}=\frac{1}{2} \cdot \rho \cdot v^{2} \cdot A \cdot C_{\mathrm{D}}$ 


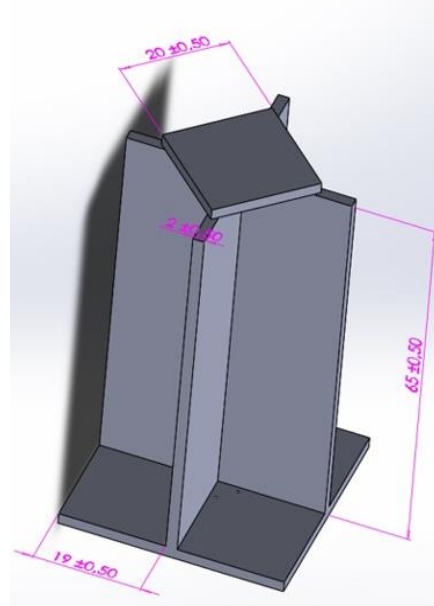

(a)

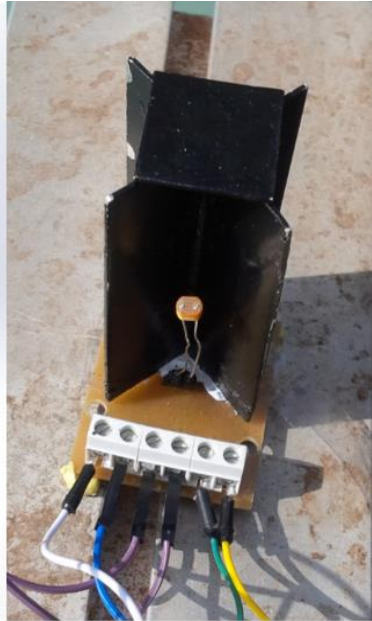

(b)
Figure 10. Luminosity sensor: (a) 3D model, (b) prototype.

\subsection{Solar tracking controller system}

The control system ensures the automatic tracking of the solar concentrator, according to the optimal point of the solar radiation captured, through a controllable operation of the motors which allows the azimuthal and tilt orientation of the collector. To ensure the tracking of the sun, it was applied a system control which uses a luminosity sensor, due to its low cost and good accuracy. The light sensor receives the information about the sun position through the incident radiation on a photosensor, the LDR. This electronic component consists of a semiconductor material whose resistance varies with the intensity of the light source (in this specific case of solar radiation, Cortez, 2013). This information is transmitted by the two pairs of LDRs (one pair for the control of the azimuth angle and another for the collector tilt) to the microcontroller which operates the motors to position the collector towards the sun. The sensor was developed by taking the example of a widely used model in academic solar concentration systems, as shown in Fig. 10.

To determine the system sensitivity an analysis of voltage variation of each LDRs as a function of the angle of incidence of radiation was performed. For this analysis, the pair of LDRs that control the azimuth movement was chosen, because this is the critical motion of the solar tracker, since the concentrator must move, for the longest day of the year (21 June), approximately $246^{\circ}$. The tests which allow the system sensitivity analysis can be divided in two groups: the first test performed is based on the variation of the angle of incidence of a light radiation, with a precision of one degree (Fig. 11); while the second test is based on the variation of the sun azimuth angle (Fig. 12).

Through the connection between the breadboard and the light sensor (shown in Fig. 12), the photosensors voltage were sent to the current standard Arduino development plat-
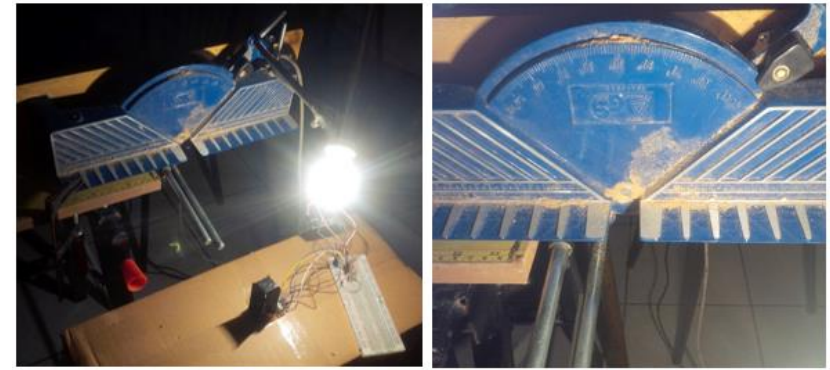

Figure 11. First experimental set up (light radiation).

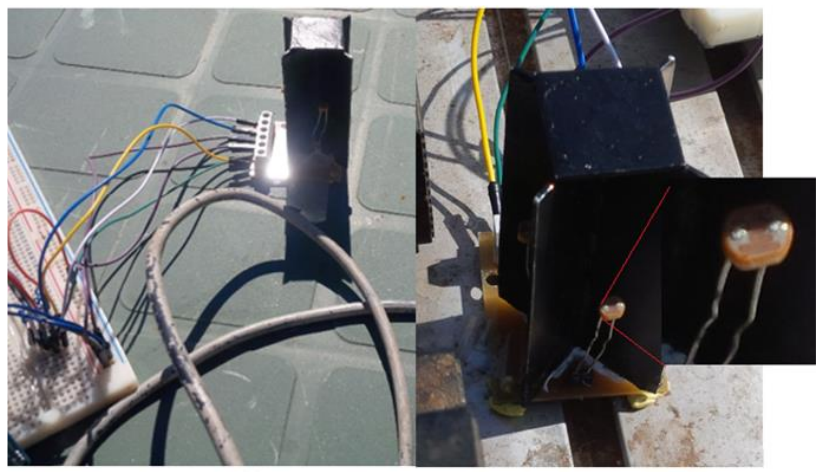

(a)

(b)

Figure 12. Second experimental set up (solar radiation).

form (Fisher and Gould, 2012), which was subsequently transmitted to a computer for reading and analysis. It is important to note that, in the absence of brightness, the voltage is $0 \mathrm{~V}$ and the maximum value is $5 \mathrm{~V}$, these values are given by the Arduino. The results show the LDRs voltage as a function of the variation of the angle of incidence of radiation. In order to facilitate the results analysis, the charts in Figs. 13 and 14 were plotted. These voltages are obtained by averaging ten values collected by the program.

The experiment starts when the voltage of both LDRs is the same (in this case approximately $2.20 \mathrm{~V}$ ), since the incident radiation is equal in both cases (angle $=0^{\circ}$ ). When this condition is verified, one LDR starts to be shaded while the other is progressively illuminated with the increase of the angle of incidence of radiation. As it can be observed in Fig. 13, the voltage difference between LDR1 and LDR2 increases with the increase of the angle of incidence until the voltage value of both LDR starts to be constant. The voltage of the LDR illuminated reaches the maximum value (close to $5 \mathrm{~V}$ ) while the LDR shadowed reaches the minimum value (close to $0 \mathrm{~V}$ ). It is also verified that the voltage of the two LDR varies almost equally from East to West and from West to East. Considering these results it was concluded that the LDRs are sensitive to radiation changes, and the variation of one degree of the angle of incidence causes a readily measurable voltage difference. 


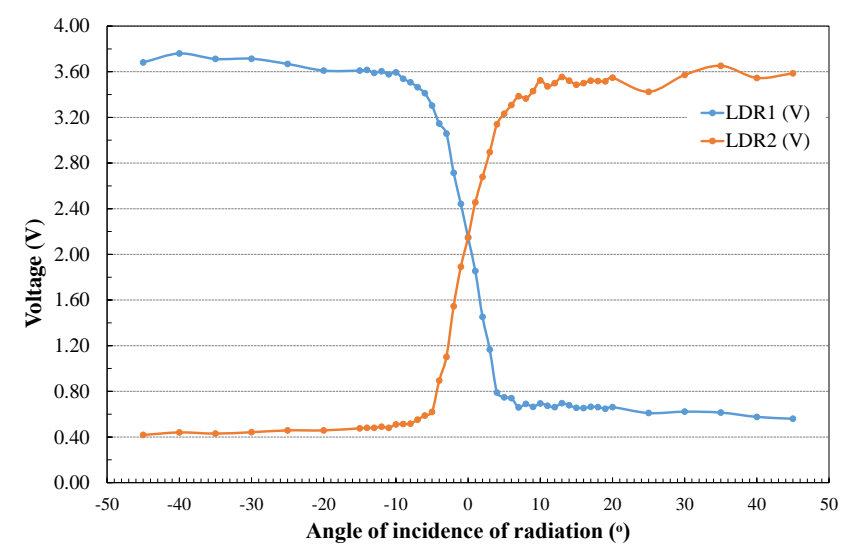

Figure 13. Variation of LDRs voltage as a function of the angle of incidence of light radiation.

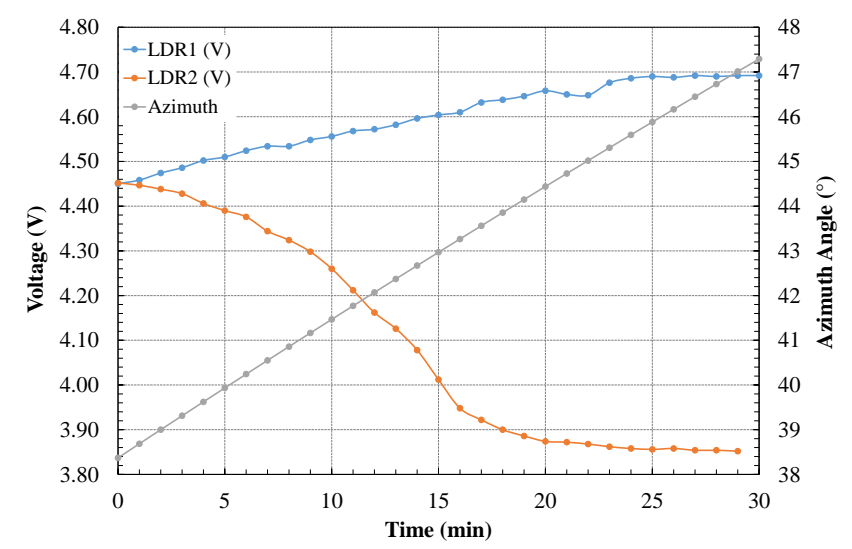

Figure 14. Variation of LDRs voltage as a function of the azimuth angle.

Maintaining the same initial conditions of the procedure explained above, the second test was performed. Through the analysis of Fig. 14 it is observed that the voltage difference between LDR 1 and LDR2 is $0.21 \mathrm{~V}$ during the first $8 \mathrm{~min}$, $0.66 \mathrm{~V}$ after $16 \mathrm{~min}$, and $0.83 \mathrm{~V}$ after $24 \mathrm{~min}$. It is noted a more sudden voltage change in the LDRs during the first $16 \mathrm{~min}$, after which the voltage tends to stabilize. It is also observed that from a variation of approximately $6^{\circ}$ of the azimuth angle, the voltage difference between LDR1 and LDR2 begins to level off (between 0.02 and $0.03 \mathrm{~V}$ ). These results allow to conclude that the movement of one degree of the sun azimuth angle implies a difference between LDR1 and LDR2 of about $0.1 \mathrm{~V}$. This may be a good starting point for the controller programming, since it should be considered the critical voltage difference between LDR1 and LDR2, from which the order to move the motors will be given. If this value is too low, the controller will continuously make adjustments to the system, resulting in an increased wear of motors. However, if it is too high, there will be a loss of performance in the system.

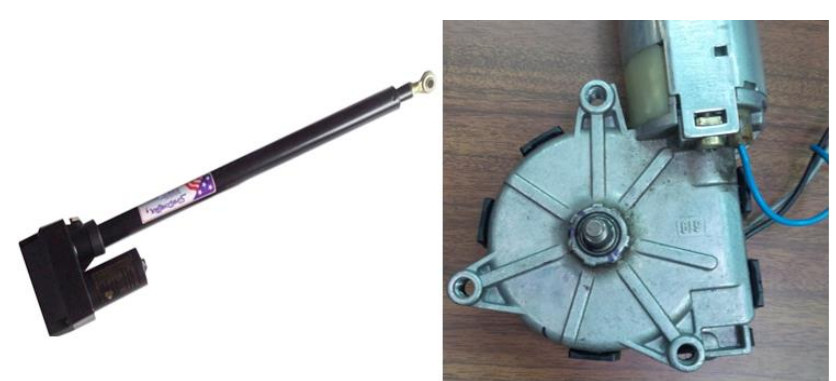

(a)

(b)

Figure 15. Tracker motors: (a) linear actuator, (b) electric motor.

\subsection{Tracking motors}

Motors applied in the solar tracker should allow the slope of the parabolic dish and its movement according to the azimuth angle of the sun. To ensure the collector's slope, a linear actuator was chosen, as shown in Fig. 15a, since is a simple system and it is sized according to the size of the parabolic dish. In order to perform the azimuthal trajectory, describing the movement according to the variation of the azimuth angle of the sun, it was necessary to develop a mechanical system capable to rotate a total of $246^{\circ}$ in a day (critical situation). For this application, the gearmotor system demonstrates to be the most practicable solution for the design, since it is a worm gear system integrated into a box, within which the output shaft drives the entire system. Gearmotors are applied in some solar tracker systems, however its cost is very high. To ensure the low cost of the solar concentrator, it was decided to manufacture a gear box using a standard motor usually used in the windshield wiper and climbing systems and lowering of the car windows, as shown in Fig. 15b. To design the gearmotor system, the transmission ratio is the most important parameters. However the motor sensitivity influences this parameter and so, it needs to be controlled. To determine the motor sensitivity a test similar to the sensor sensitivity was carried out, through which it is observed that the ideal transmission ratio is $16: 1$.

\subsection{A low cost system}

One important aim of this project is the development of a low cost solar tracker, so during the project, the search for cost effective solutions was mandatory. The cost analysis can be divided in three groups of components: controller system, structure and motors. As mentioned above, to minimize costs and considering its good accuracy, a control system which uses a luminosity sensor was constructed and its estimated costs was about EUR 52. Tracking motors are always a huge problem in terms of tracking systems costs, mainly for the azimuthal motor. To avoid heavy costs, a simple actuator was bought and a gearmotor was constructed using a standard motor, for a grand total of EUR 370. In reference to the solar tracker structure which involve all the fixing parts, 


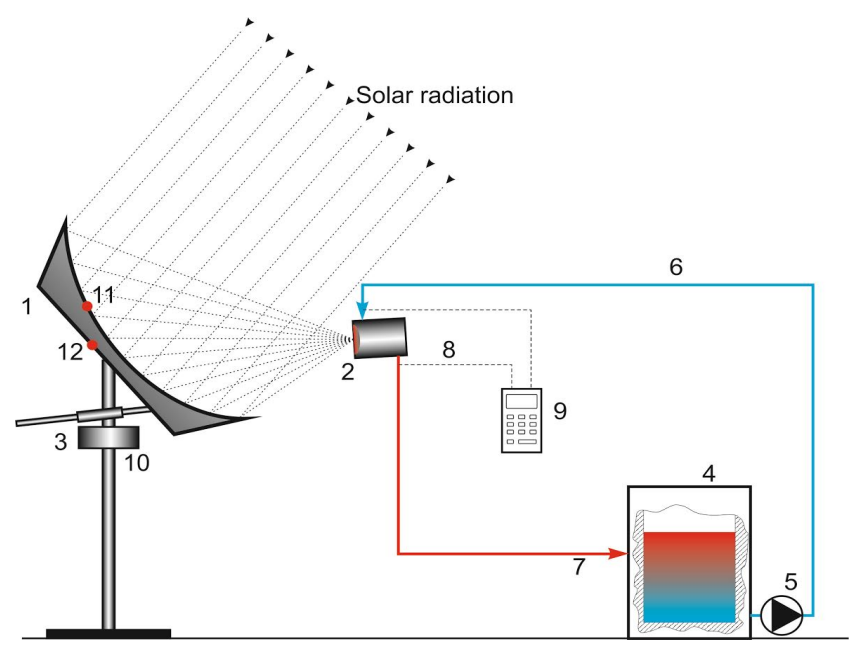

Figure 16. Experimental set up of the solar dish concentrator.

the mast, shaft, bearings, connection elements, machining, welding and painting processes, the cost amounts to only EUR 135. Proceeding to the sum of the values presented and adding the cost of the coating collector and the receiver, the total cost of the system is about EUR 750, which is really an interesting value when compared to similar structures available in the market. Therefore it is concluded that the developed system fulfil the aim, ensuring a good reliability at low cost.

\section{Testing facility}

To analyse the potential of the solar dish concentrator, a test facility was developed, as schematically presented in Fig. 16. Through this testing facility, experimental tests were carried out in order to evaluate the response and the efficiency of the system. The experiments were conducted in clear sky days and the velocity of the wind was registered from the meteorological information. The experimental set up consists of a collector (1) which collects the solar radiation and reflects it at the receiver (2); a dual axis solar tracker (3), controlled by the control system (10), ensures the correct tracking of the sun. A $4 \mathrm{~L}$ insulated water tank (4) is heated by the receiver; a pump (5), is placed into the tank to ensure the circulation of the water, at a flow rate of about $4.73 \times 10^{-5} \mathrm{~m}^{3} \mathrm{~s}^{-1}$, and two transparent and flexible PVC tubes ensure the cold water inlet (6) at the receiver and the hot water outlet (7). Two thermocouples (8) placed in the tubes next to the receiver allow the measurement of the water temperature which can be read by the digital thermometer (9). Two other thermocouples placed on the front (11) and back (12) of the collector, enable the temperature measurement of these two surfaces. The final prototype can be observed in Fig. 17.

Considering the experimental set up shown in Fig. 16, four tests were performed:

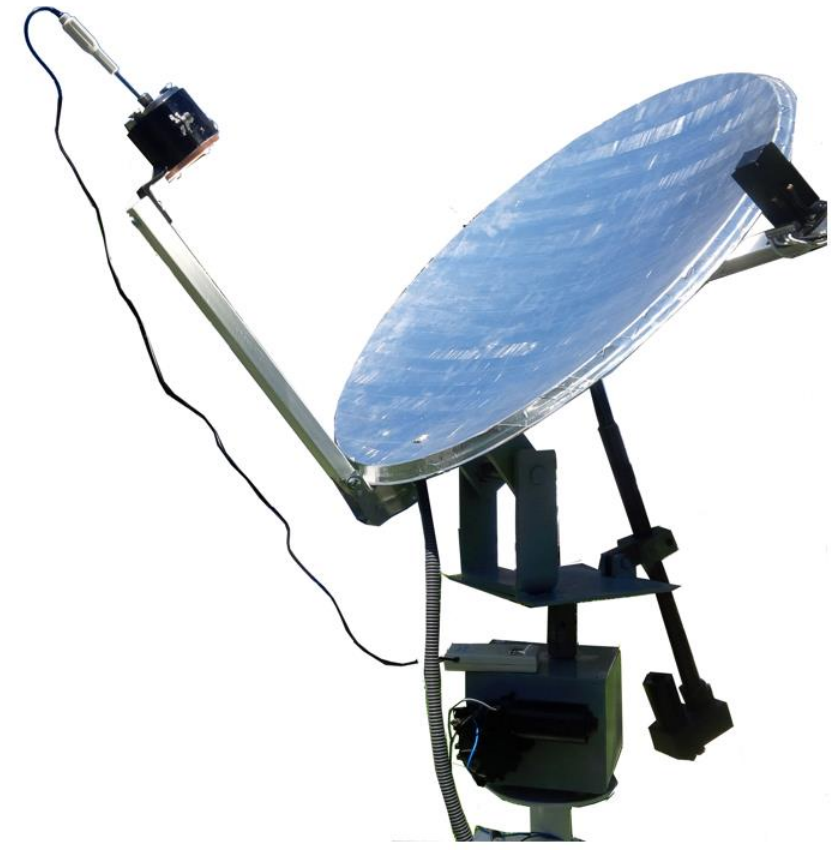

Figure 17. Solar dish concentrator prototype.

- Experiment 1: the first test analyses the response of the system without activation of the solar tracker, in order to demonstrate the performance losses resulting from the non-activation of the solar tracker, highlighting the importance of this system in this type of applications.

- Experiment 2: this test evaluates the influence of the reflective surface. For the analysis two collectors were used, one with a lower reflectivity value $(0.8)$, represented in the final results as "Collector 1", and another with a higher reflectivity value (0.96), namely "Collector 2". The parameters measured were the internal and external receiver temperature (without water circulation) and the efficiency of the system during the water heating throughout the day.

- Experiment 3: this test allows to evaluate the thermal efficiency as function of the receiver position.

- Experiment 4: the fourth test evaluates the thermal efficiency as function of the solar irradiance. For this purpose the results obtained on 10 August and 28 September are compared.

\section{Results and discussion}

\subsection{Response without tracking system activation}

By analysing the date in Fig. 18, it is clear that the water warms up during the first $10 \mathrm{~min}$, at approximately $0.2^{\circ} \mathrm{Cmin}^{-1}$. From this moment the temperature in the inlet 


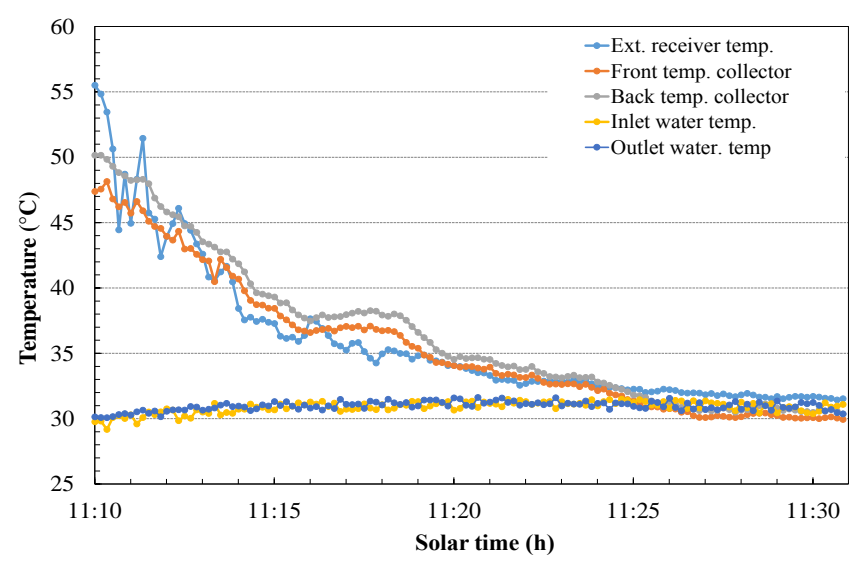

Figure 18. Variation of the temperature as a function of time without activation of the tracking system.

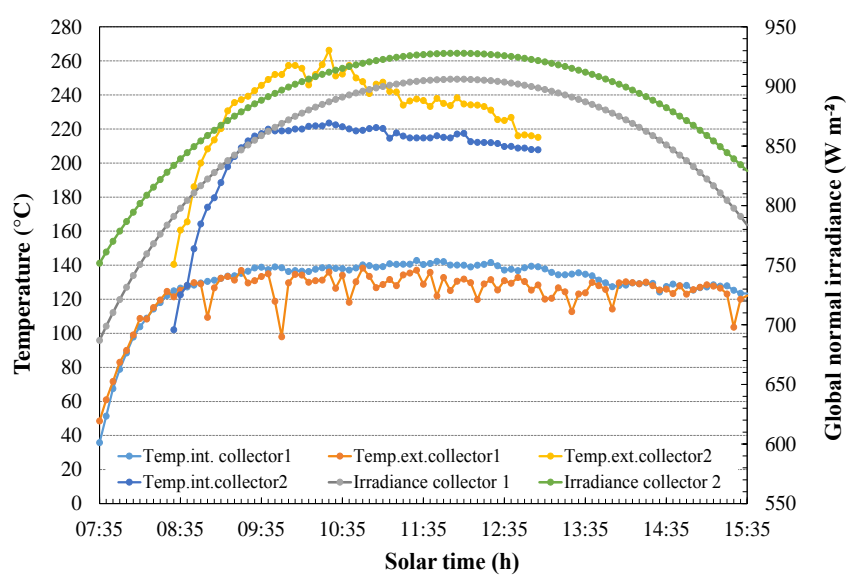

Figure 19. Variation of the internal and external receiver temperature (without water circulation).

and outlet of the receiver is approximately the same, $31.2^{\circ} \mathrm{C}$. With reference to the temperature of the absorber surface of the receiver, there has been a sharp decline in the early stages, varying around $15^{\circ} \mathrm{C}$ during the first $5 \mathrm{~min}$, by the fact that the concentration area of solar rays moves away from the center to the edges of the receiver, so the fins started to cool. Since the concentration area moves away from the center with time, the trend is that the receiver temperature will become in equilibrium with the ambient temperature. This is why after the first $5 \mathrm{~min}$ it is observed a decrease of about $0.5^{\circ} \mathrm{Cmin}^{-1}$ and after $15 \mathrm{~min}$ the temperature decreases $0.1^{\circ} \mathrm{Cmin}^{-1}$. This experimental test demonstrates that $1^{\circ}$ in azimuth angle variation causes significant losses in the system, considering that on this day and time the sun "moves" at a speed of approximately $0.29^{\circ} \mathrm{C} \mathrm{min}^{-1}$.

\subsection{Influence of the reflective surface}

In Fig. 19 it is clearly observed that with a solar concentrator with a higher reflectivity value, the receiver can reach about twice the external temperature and that the temperature difference between the internal and external receiver temperature is also higher. The higher the temperature of the absorber surface, the greater the convection losses, and thus the higher the temperature difference between the internal and external receiver surface. Looking at the external temperature during the day, it is noted that, after the maximum temperature is reached on the receiver surface, this remains approximately constant varying only with the increase of the wind speed. The decrease in temperature occurs mainly from 15:00 LT, since the irradiance will sharply reduce from that time of day. For these reasons, it is concluded that the system allows a good exploitation of solar radiation, keeping the maximum temperature for, approximately, $4 \mathrm{~h}$.

Comparing the experimental results obtained with both collectors (Figs. 20, 21), it is observed that the thermal performance of the collector with a high reflectivity is higher when compared with the other collector. In fact, the maximum temperature recorded at the receiver absorber surface was only $57^{\circ} \mathrm{C}$ against $142^{\circ} \mathrm{C}$ in the test with a collector with a higher reflectivity. In addition, in the first test the maximum water temperature was $42.5^{\circ} \mathrm{C}$, reached after $6 \mathrm{~h}$ and $15 \mathrm{~min}$ of operation and in the second one this temperature was $51^{\circ} \mathrm{C}$ reached after $3 \mathrm{~h}$. This confirms that the application of a collector with a high reflectivity leads to a significant increase in system efficiency. On the other hand, comparing the theoretical maximum temperature presented in Fig. 3, it is clearly observed that independently of the reflective surface, the maximum temperature reached by the receiver in the experimental tests is lower. This fact is essentially due to the thermal inertia of the receiver's material which was not considered in the theoretical study, but also due the external factors, such as wind and clouds that interferes during the test.

\subsection{Influence of the receiver position}

The orientation of the receiver to the collector's surface was changed in order to assess the influence of the slump error of the receiver in the system performance. For that four receiver's slump angles were tested, the ideal position (aligned with the optical axis of the collector), and with offsets 10 , 15 and $30^{\circ}$ in relation to the ideal position. The results, presented in Fig. 22, show that the maximum water temperature reached by the system, in clear sky conditions, is $46^{\circ} \mathrm{C}$. This value is obtained first in the ideal position and decreases with the increase in the offset angle. In all cases the temperature difference is higher in the early stages, due to the high temperature reached by the fins inside the receiver immediately before the water circulation, stabilizing after an hour and a half. It is also observed that the worst case $\left(30^{\circ}\right.$ offset) leads 


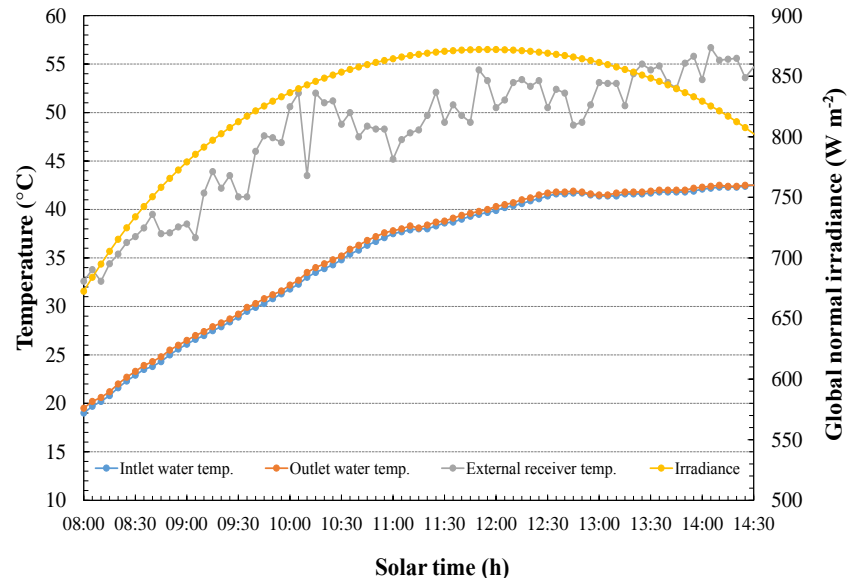

Figure 20. Variation of the system temperature as a function of time with a collector with a lower reflectivity.

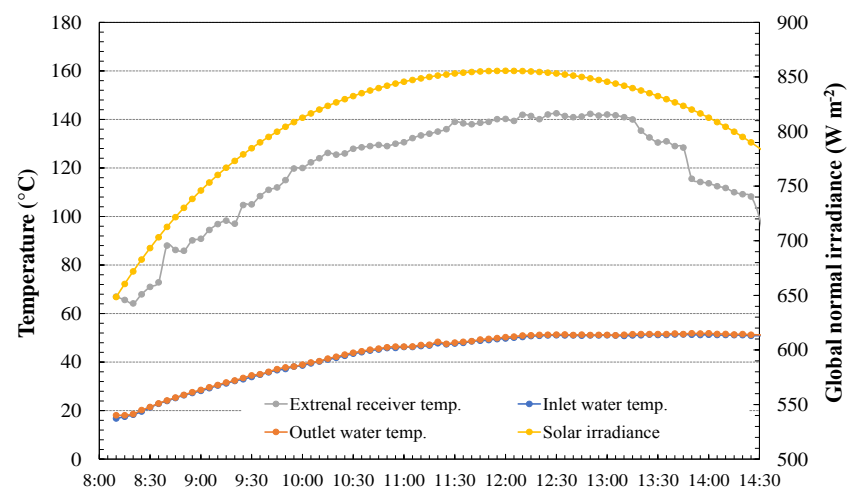

Solar time (h)

Figure 21. Variation of the system temperature as a function of time with a collector with a higher reflectivity.

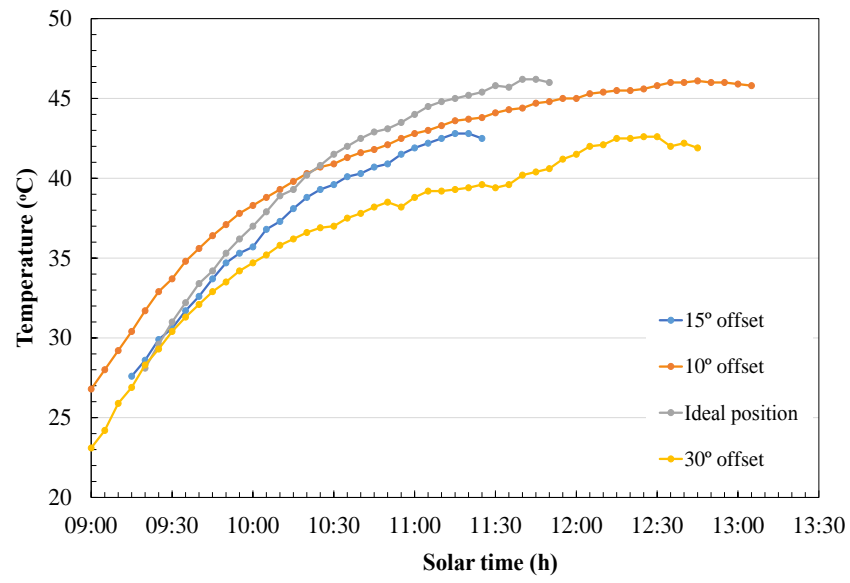

Figure 22. Variation of water temperature at external receiver surface over time.

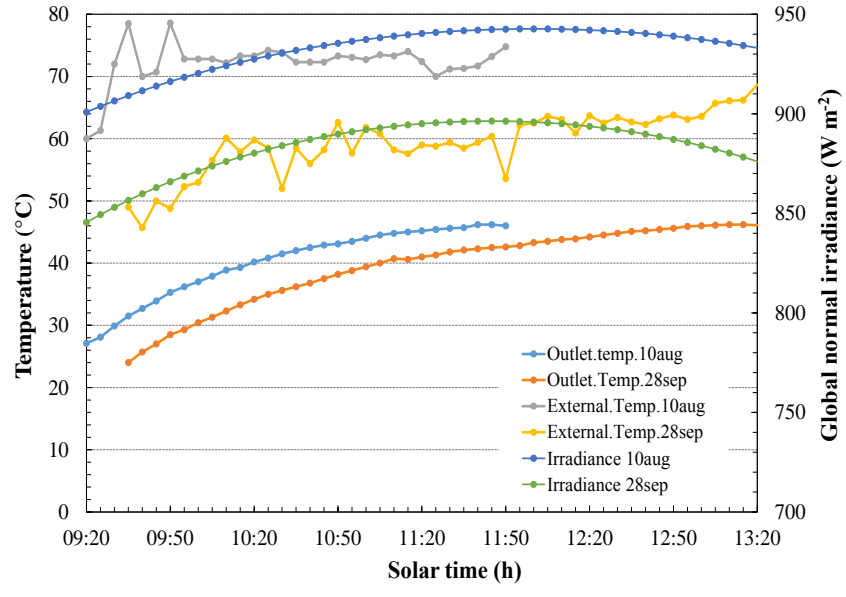

Figure 23. Temperatures recorded on 10 August and 28 September.

to a thermal efficiency losses of about $20 \%$. The ideal position maximizes the receiver's surface temperature approximately $78.5^{\circ} \mathrm{C}$, leading to a maximum value of the water temperature of about $46.2^{\circ} \mathrm{C}$, whereas in the worst case the receiver temperature is only $75.8^{\circ} \mathrm{C}$, which led to a water temperature of approximately $42.5^{\circ} \mathrm{C}$.

\subsection{Influence of the solar irradiation}

Tests were carried out in two occasions when the solar irradiation is different and the results obtained are shown in Fig. 23. The data shows that the receiver's surface temperature is $10^{\circ} \mathrm{C}$ higher for the high irradiation condition (irradiance is $46.3 \mathrm{~W} \mathrm{~m}^{-2}$ higher). The temperature reached by the water on 10 August is $46^{\circ} \mathrm{C}$, after $2 \mathrm{~h}$ and $30 \mathrm{~min}$ of system operation, while on 28 September, the same water temperature was reached after $4 \mathrm{~h}$ of operation. Regarding the receiver's efficiency recorded on 10 August this is, on average, $20 \%$ higher than that obtained on September (low irradiation). This efficiency difference is less in the collector, just $10 \%$ higher than August, as it can be observed in Fig. 24. Regarding the efficiency, it is important to mention that the maximum peaks observed are mainly due to the clouds, which block the direct solar radiation, and the wind speed variation. The little fluctuations are essentially due to errors associated to the thermocouples considering that the variation of temperature at each time is low. From the results, it can be concluded that a difference in solar irradiance of approximately $46 \mathrm{~W} \mathrm{~m}^{-2}$ leads to a significant loss of system efficiency. 


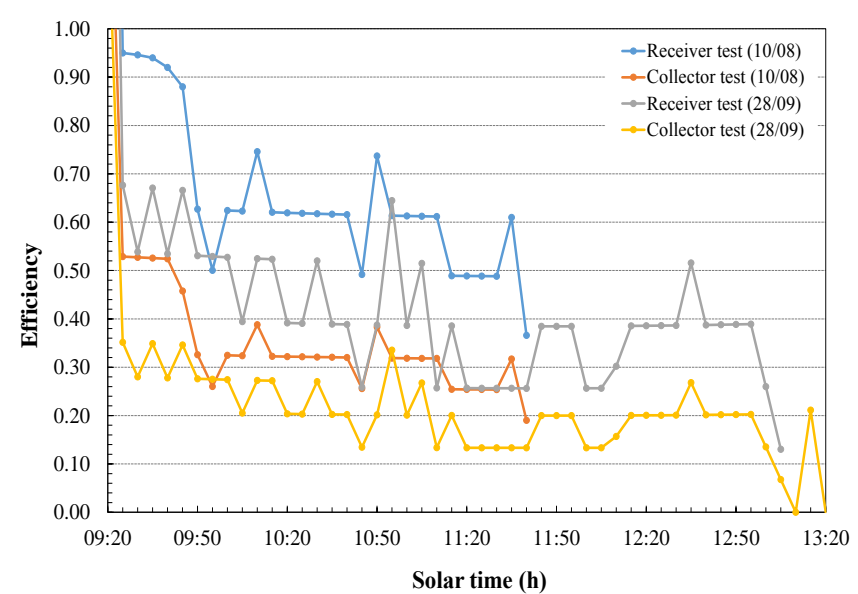

Figure 24. Efficiencies recorded on 10 August and 28 September.

\section{Conclusions}

In this paper, a solar dish concentrator and its tracking system was designed and constructed. During the study of this technology, three elements are highlighted, the collector, the receiver and the tracking system. Furthermore, it was mentioned that costs play an important role in this solar application, so, the development of a low cost system is crucial.

A relevant factor on performance analysis is the receiver position. This study concludes that, the higher the mismatch in relation to the optimal position, the lower the system performance, because, the solar radiation reflected by the concentrator is reduced. It shows that a small change of the optimal position can lead to an efficiency loss of up to $20 \%$. These results also highlight to the need of implementing an efficient tracking system which ensures the total track of the sun's path during the day. As the experimental test of the variation of the receiver temperature without tracking system demonstrates, $1^{\circ}$ of sun motion, through the azimuth angle, is enough to create significant losses in the system. Comparing the results obtained in Sect. 5.1 with a full sun tracking, it is observed that if the tracking system is not activated, the thermal inertia of the absorber surface prevents the water temperature to rise to acceptable values. This is not the case in the others experiments, since the absorber surface reaches temperatures above $55^{\circ} \mathrm{C}$ and maintains this temperature throughout the experiment. Another important factor is the atmospheric conditions. As it was observed from the results, the direct losses to the environment, clouds and wind lead to great losses of efficiency. Clouds minimize the radiation concentrated in the receiver and the wind increases the heat losses by convection. Since this factor cannot be controlled, it is important to ensure minimal errors during the design of all solar concentrator elements. However, it is important to refer that the structure of the solar receiver need to be improved, to minimize losses to the environment and increase the solar energy density that can be absorbed. In rela- tion to the collector reflectivity, the experimental results confirm that an increase from 0.8 to 0.96 leads to a significant increase of the system efficiency. Comparing the two collector types, on the same conditions of clear sky and moderate wind speed, and considering that the incident irradiation is higher for the collector with a lower reflectivity, it appears that the efficiency can be $20 \%$ higher on the collector with a higher reflectivity. Therefore the collector reflectivity is a fundamental characteristic in this type of projects.

This work shows that there is a good potential of use of solar dish concentrators. The collector may be selected depending on the fluid temperature to be achieved. The aim of this application can be the production of steam/vapour for the production of electrical energy, and for that it can be chosen a collector with a bigger diameter and a reflectivity close to the unit. On the other hand, if the aim was the production of hot water for daily consumption, it can be chosen a collector with smaller dimensions. Nonetheless it is required, for both situations, a reflectivity close to the unit.

\section{Data availability}

This article is based on work developed during a Master Thesis. The URL of the Master Thesis is available to check all the data and additional information that the reader considers relevant (http://hdl.handle.net/1822/39352).

The data cited in the article can be found in the data repository PANGAEA https://doi.pangaea.de/10.1594/ PANGAEA.867482.

Edited by: D. Pisla

Reviewed by: two anonymous referees

\section{References}

Allaby, M.: Fog, Smog and Poisoned Rain, 1st Edn., VB Hermitage, USA, 2003.

Cengel, Y.: Heat and Mass Transfer Fundamental \& Applications, 5th Edn., McGraw-Hill Education, USA, 2015.

Cortez, R.: Sistema de Seguimento Solar em Produção de Energia Fotovoltaica, Master thesis, Faculty of Engineering of Porto, Portugal, 2013.

CSP WORLD: CSP World Map, Spain, available at: http://www. cspworld.org/cspworldmap (consulted: 28 October 2015), 2015.

Duffie, A. and Beckman, W.: Solar Engineering of Thermal Processes, 2nd Edn., John Wiley \& Sons, USA, 1991.

Fernandes, E. O., Marques, V. S., Rodrigues, J., Pimenta, C., Aguiar, C., Nunes, J., Rodrigues, B., Tirone, L., Veríssimo, M., Correia, M., Lopes, J. A. P., Mendes, J. F., Joyce, A., Cruz, J., Bicudo, C., Patrão, G., Mendes, C., Matos, J., Soares, H., Correia, N., Almeida, B., Serranho, H., Sarmento, A., Gonçalves, L. A., Estanqueiro, A., Curado, A., Barreto, M., Sá da Costa, A., and Schmidt, L.: Energias Renováveis, 1st Edn., Atelier Nunes e Pã, Lisbon, 2009.

Ferreira, A. C., Nunes, M. L., Teixeira, J. C. F., Martins, L. A. S. B., Teixeira, S. F. C. F.: Thermodynamic and Economic Optimiza- 
tion of a Solar-powered Stirling engine for Micro-Cogeneration Purposes, University of Minho, Portugal, Energy, 111, 1-17, doi:10.1016/j.energy.2016.05.091, 2016.

Fisher, D. and Gould, P.: Open-Source Hardware Is a Low-Cost Alternative for Scientific Instrumentation and Research, Modern Instrumentation, 1, 8-20, doi:10.4236/mi.2012.12002, 2012.

Fraunhofer ISE: Current and Future Cost of Photovoltaics, Longterm Scenarios for Market Development, System Prices and LCOE of Utility-Scale PV Systems, Study on behalf of Agora Energiewende, 2015.

Gorjan, S., Tavakkoli Hashjin, T., Ghobadian, B., and Banakar, A.: Thermal Performance of a Point-focus Solar Steam Generating System, 21st Annual International Conference on Mechanical Engineering, ISME2013, 7-9 May 2013, School of Mechanical Eng., K. N. Toosi University, Tehran, Iran, 2013.

Hess, J.: Analytic solutions for potential flow over a class of semi-infinite two-dimensional bodies having circular-arc noses, J. Fluid Mech., 60, 225-239, 1973.

Holman, J.: Heat Transfer, 4th Edn., International Student Edition, McGraw-Hill Kogakusha, Ltd, 1976.

Kalogirou, A.: Solar Energy Engineering: Processes and Systems, 2nd Edn., Academic Press, USA, 2014.

Mohamed, F. M., Jassim, A. S., Mahmood, Y. H., and Ahmed, M. A. K.: Design and Study of Portable Solar Dish Concentrator, International Journal of Recent Research and Review, 3, 52-59, 2012.

Mousazadeh, H., Keyhania, A., Javadib, A., Moblia, H., Abriniac, K., and Sharifi, A.: A Review of Principle and Sun-Tracking Methods for Maximizing Solar Systems Output. Renew. Sust. Energ. Rev., 13, 1800-1818, doi:10.1016/j.rser.2009.01.022, 2009.

Nogueira, H.: Manual das Energias Renováveis - o Futuro do Planeta, 1st Edn., AECOPS, Lisbon, 2010.

Kurup, P. and Turchi, C.: Initial Investigation into the Potential of CSP Industrial Process Heat for the Southwest United States, National Renewable Energy Laboratory, USA, available at: http://www.nrel.gov/docs/fy16osti/64709.pdf (last access: 15 December 2015), 2015.
Rabl, A.: Comparison of Solar Concentrators, Sol. Energy, 18, 93 111, doi:10.1016/0038-092X(76)90043-8, 1976.

Ripasso: Ripasso Stirling Hybrid, Sweden, available at http://www.ripassoenergy.com/ (last access: 10 February 2016), 2016.

Robert, Y. M.: Wind Effects on Convective Heat Loss from a Cavity Receiver for a Parabolic Concentrating Solar Collector, Sandia National Laboratories, California, 1993.

Simbolotti, G.: Concentrating Solar Power, IEA-ETSAP and IRENA, available at:

http://www.irena.org/DocumentDownloads/Publications/ IRENA-ETSAPTechBriefE10ConcentratingSolarPower.pdf, last access: 10 September 2015, January 2013.

SolarGis: Maps of Global Irradiation, GeoModel Solar, Nova Scotia Canada, available at: http://solargis.info/doc/ free-solar-radiation-maps-GHI, last access: 4 April 2015, 2010.

Solartron: How does a Solar Concentrator Solar Dish Work, Solartron Energy System Inc., available at: http://www.solartronenergy.com/solar-concentrator/ how-does-a-solar-concentrator-work/, last access: $20 \mathrm{Au}$ gust $2015,2010$.

Stine, W. B. and Geyer, M.: Power from the Sun Book, USA copyright $^{(} 2001$ by Stine, W. B. and Geyer, M., available at: http://www.powerfromthesun.net/book.html, last access: 5 February 2015, 2001.

Steinfeld, A. and Schubnell, M.: Optimum Aperture Size and Operating Temperature of a Solar Cavity-Receive, Sol. Energy, 50, 16-25, 1993.

Thakkar, V.: Performance Analysis Methodology for Parabolic Dish Solar Concentrators for Process Heating Using Thermic Fluid, IOSR Journal of Mechanical and Civil Engineering (IOSRJMCE), 12, 101-114, doi:10.9790/1684-1212101114, 2015. 